\title{
Empowering ASCl's support of physician-scientists through stronger institutional connections
}

\author{
Kieren A. Marr, W. Kimryn Rathmell, John B. Hawley, and Karen D. Guth
}

\begin{abstract}
The American Society for Clinical Investigation (ASCI), a nonprofit honorary society, was established to support physician-scientists by serving as a benchmark of excellence in medical research, a forum to celebrate advances in medicine, and a vehicle to communicate advances that bridge basic and translational research and their implementation across the growing myriad of medical specialties. A core intention of the Society is to engage the medical research community broadly through transparent communications of our activities and initiatives with the institutions that comprise the base for our membership. Recognizing the importance in identifying and actuating a strategy to support the Society's broad mission, the current leadership has undertaken a strategic plan that initiates with the goal of revamping its Institutional Representatives program. While the Society has grown with the historical privilege of close connections to institutions through an informal web created largely by the elected membership, we aim to improve institutional engagement towards overall goals of embracing and enhancing diversity of our community and implementing future collaborative programs to support physician-scientists. We briefly review ASCl's history, mission, and structure, and present the blueprint of the new Institutional Representatives program.
\end{abstract}

that ASCI Council members "have two duties - one pleasant and the other not so pleasant. The pleasant duty is to attend [the annual meeting] and to hear reports of exciting research with implications far beyond the boundaries of medicine. The Council's less pleasant duty is to review each year the careers of 250 clinical investigators who have been nominated for membership. Selecting 80 members from this pool is difficult and often unsettling for the Council as well as for the candidate. Having one's career reviewed by the ASCI Council is like having a mid-career checkup - only the sigmoidoscopy is omitted." A third Council duty goes unmentioned, implied, although certainly not unappreciated - the fiduciary responsibility inherent to governing a not-for-profit organization. At its simplest, this duty is financial, ensuring that the ledger is balanced for current and future needs; however, the perhaps more complex responsibility is that which engages on the matter of relevance, purpose, and focus of an organization.

\section{$\mathrm{ASCl}$ in brief}

The ASCI was founded from a rebellion. Young researchers in the early 1900s were sidelined from presenting their work at major medical congresses, then the primary means to communicate advances, even while their work represented the most innovative, forward-thinking advances in clinical science. Their approach to research emphasizing physiological methods was at the time ushering in the disruptive foundation of evidence-based medicine. The Society was first proposed in 1907 by Samuel Meltzer, a relatively new member of the Rockefeller Institute (later becoming Rockefeller University). At the American Medical Association meeting, he proposed the creation of a new organization focused on clinical research; in 1909, Dr. Meltzer provided introductory remarks for the first ASCI meeting, incorporated the previous year with a chief objective for "the advancement of medical science" (1). Two years later would witness the release of the Flexner Report, which transformed medical education from a predominately for-profit enterprise with widely divergent curricula and expertise to a universitybased endeavor with a consistent curriculum and result (2).

Since this founding, the ASCI has become one of a handful of organizations led by, and representing, physicianscientists who were elected on the basis of their scholarly achievements. While much has been written about the purpose (and plight) of the ASCI, Dr. Joseph Goldstein's 1986 ASCI Presidential Address "On the origin and prevention of PAIDS (Paralyzed Academic Investigator's Disease Syndrome)" provides a durable reference (3). In this address, Dr. Goldstein noted

\section{Mission, structure, and strategy}

The ASCI has survived 111 years on the strength of core objectives: electing highly qualified physician-scientists, convening an annual meeting that showcases advances in medical research, and publishing relevant content in the various fields of medicine in the Journal of Clinical Investigation (JCI). While the ASCI endured for over a century with its original objectives intact, it did so without an articulated mission until 2014, when the Council adopted the following as a working Mission Statement: "The ASCI seeks to support the scientific efforts, educational needs, and clinical aspirations of physician-scientists to improve human health" (4). Other recent initiatives were added to support key objectives and ASCI's commitment to its community: the Stanley J. Korsmeyer Award (started in 1998), the Young Physician-Scientist Awards (2013), the ASCI/Harrington Prize for Innovation in 


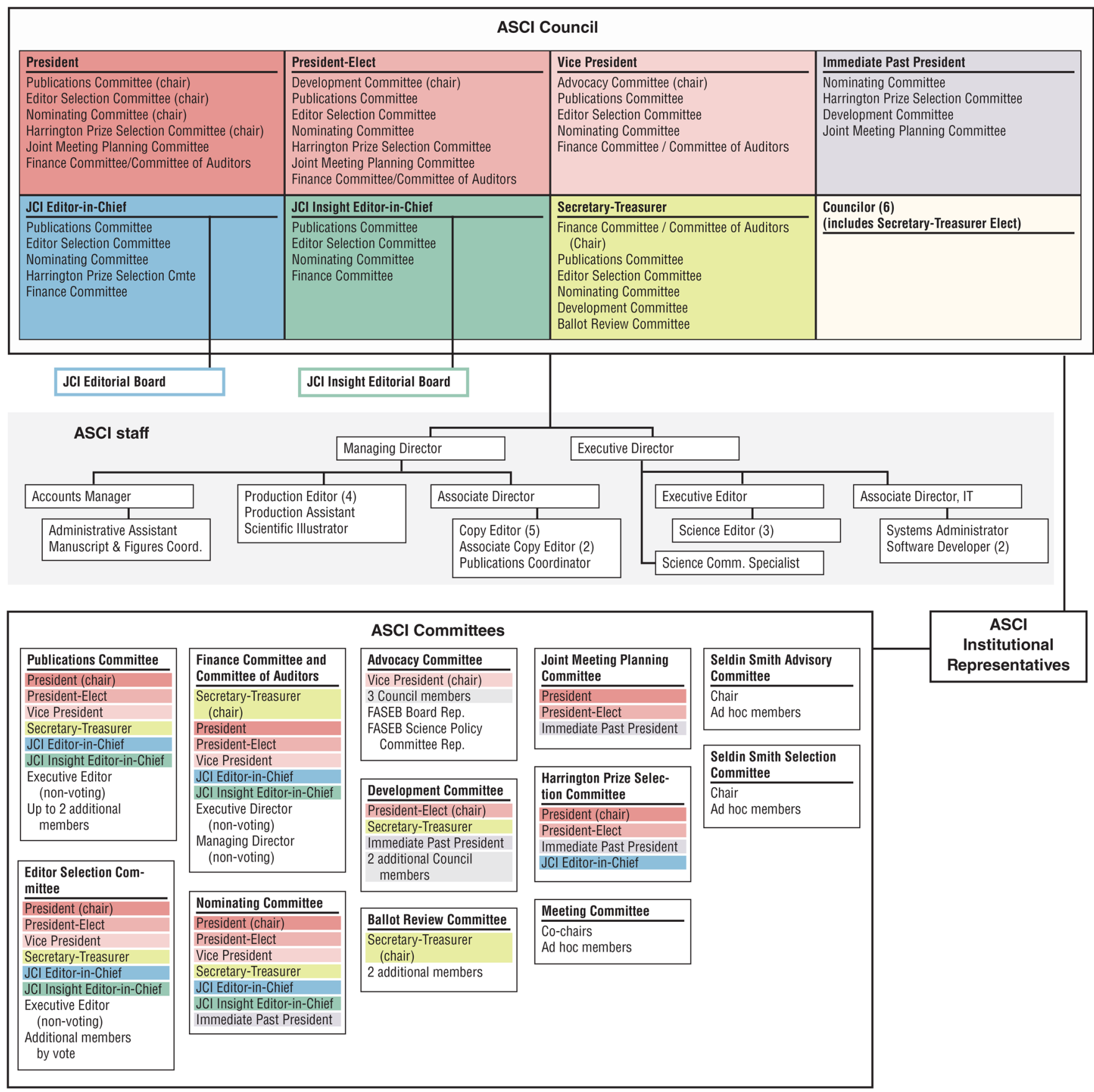

Figure 1. Organizational structure of the American Society for Clinical Investigation, 2019.

Medicine (2014), the Donald Seldin Holly Smith Award for Pioneering Research (2015), and JCI Insight (2016).

In the last few years, the ASCI Council has undertaken a review of its structure and programs, leading to the formation of committees that will ultimately serve to broaden participation from the membership while focusing on specific domains of particular importance to the organization. A simplified organizational chart is shown in Fig- ure 1. Executive leadership and the elected Council oversee operations of the JCI, JCI Insight, and multiple committees. The Meeting Committee oversees the Young Physician-Scientist Awards program. The Development Committee is tasked with building philanthropic support for ASCI programs in support of physician-scientists across the career spectrum. The Advocacy Committee is now in place to focus on the ASCI's position in the policy arena, notably its relationship to external advocacy groups such as the Federation of American Societies for Experimental Biology (FASEB), and its own identified priorities (for example, a 2018 JCI publication, "Balancing dual demands on the physician-scientist workforce"). The Publications Committee now oversees a publication portfolio expanded with the 2016 launch of JCI Insight, now publishing as much original research as the JCI and providing an additional - and 
respected - venue for research from the ASCI membership and the broader biomedical community.

Acknowledging the need to develop a strategy to support the recently described ASCI mission, the 2018-2019 Council built upon a membership-wide SWOT (strength, weakness, opportunities, and threats) analysis, identifying two strategic priorities and actionable items for the next Council cycle: 1 ), to clarify, articulate, and codify transparent organizational structures and processes; and 2), to develop, launch, and maintain programs to increase the value of the organization to ASCI members and the broader community. Initiatives and outcomes, which include steps to reinforce the ASCI's commitment to diversity, inclusion, and professionalism, will be presented in more depth at the upcoming April 2019 annual meeting. In preparation for that meeting, ASCI member institutions are being called upon to develop a newly invigorated Institutional Representatives program.

\section{The ASCI Institutional Representatives program}

The ASCI Council has been focusing on its Institutional Representatives (IR) program as an underutilized tool to galvanize members, to recognize rising stars in the community across medical disciplines, and to support underrepresented and underserved early-career physician-scientists. The program, started in 1998 under then President Gary Koretzky, was envisioned to facilitate communication between the ASCI and institutions represented by membership (5). Some 20 years later, participation in the program, both from the perspective of institutions themselves and those assigned to (or volunteering in) the representative role, is variable. Some representatives are highly engaged, yet lack institutional support, while other institutions are highly engaged yet don't have a defined representative.
The ASCI itself has fed some of the variable engagement by not adequately defining roles and expectations.

Over the 2019-2020 term, the Council endeavors to revitalize the Institutional Representatives program. The Council hopes that this revitalization will ensure that an engaged member is in the representative role; the representative is supported by the institution and the Society; the representative is well-versed in the Society's objectives, mission, and programs; and the representative brings institutional priorities and concerns about physician-scientists to the ASCI for discussion.

After the ASCI's annual meeting in April 2019, the Council will call on institution Deans, Chief Executive Officers, Presidents, or leaders in similar positions to appoint, by mid-summer 2019, a representative for a fixed term and to provide a small percentage of protected time for the representative, accompanied by an expectation that representatives attend each ASCI annual meeting during their terms. The Council envisions providing partial financial support for the representative's meeting attendance and expects that institutional leaders will demonstrate their commitment to their representatives by supporting their meeting travel and active participation in Society activities.

The Council has heard that the Society is Internal Medicine-focused and that it doesn't adequately represent the work being done by the broad community of physician-scientists. By having high-level institutional leaders appoint representatives, there is greater potential for representatives to be more cognizant of an institution's research portfolio across departments and divisions, and the portfolio's impact on the enterprise's continuum of care. In turn, these representatives will be better versed in potential leadership positions within the ASCI and the opportunity for expanded influence through these positions.
Of particular interest to the Council is diversity and inclusion. These terms are not isolated to gender and race, although these areas unfortunately continue to be significant ones to be addressed. Beyond these areas, the Council wants to ensure that high-impact research outside traditional disciplines and that in emerging fields has a home in the Society, at its meeting, and in its journals. This will entail understanding and mentoring physician-scientists in training who have different needs and whose contributions can't be assessed in a traditional manner. The Council sees the Institutional Representatives program being a critical component of mentoring between meetings. At annual meetings, the ASCI will undertake expansion of mentoring and career-development efforts, creating new opportunities for early-career physicianscientists based on representatives' feedback. Ultimately, the Council hopes for an accumulation of best practices from institutions that can serve as a platform for those entering mentoring roles - and for those being mentored.

The Council looks forward to working with the ASCI community in the coming years on these efforts and welcomes your feedback at staff@the-asci.org.

1. Howell JD. A history of the American Society for Clinical Investigation. J Clin Invest. 2009;119(4):682-697.

2. Flexner A. Medical education in the United States and Canada. From the Carnegie Foundation for the Advancement of Teaching, Bulletin Number Four, 1910. Bull World Health Organ. 2002;80(7):594-602.

3. Goldstein JL. On the origin and prevention of PAIDS (Paralyzed Academic Investigator's Disease Syndrome). JClin Invest. 1986;78(3):848-854.

4. Jain MK. 2015 American Society for Clinical Investigation Presidential Address: Advancing the mission. JClin Invest. 2015;125(9):3308-3315.

5. Koretzky GA. The future of the ASCI (American Society for Clinical Investigation): a lesson from the 2000 presidential election. J Clin Invest. 2001;108(7):S3-S7. 